\title{
VIII. On the size of molecules
}

\section{N.D.C. Hodges}

To cite this article: N.D.C. Hodges (1879) VIII. On the size of molecules, Philosophical Magazine Series 5, 8:46, 74-75, DOI: 10.1080/14786447908639652

To link to this article: http://dx.doi.org/10.1080/14786447908639652

$$
\text { 曲 Published online: } 13 \text { May } 2009 .
$$

Submit your article to this journal

LII Article views: 3

Q View related articles $\asymp$ 
for any number of faults and for all the terminal arrangements that can be made out of those shown in fig. 4. The denominator of (19) is a function of $a_{i}$ and $b_{i}$. Thus

$$
\mathrm{A}_{i}=\frac{\mathrm{E} l \cos b_{i}}{a_{i} \phi\left(a_{i} b_{i}\right)} \text {, , , , . . . }
$$

[To be continued.]

VIII. On the Size of Molecules. By N. D. C. Hodges*.

TF we consider unit mass of water, the expenditure on it of 1 an amount of energy equivalent to 636.7 units of heat will convert it from water at zero into steam at $100^{\circ}$. I am going to consider this conversion into steam as a breaking-up of the water into a large number of small parts, the total surface of which will be much greater than that of the water originally. To increase the surface of a quantity of water. by one square centimetre requires the use of 000825 metregramme of work. The total superficial area of all the parts, supposing them spherical, will be $4 \pi r^{2} \mathrm{~N}$, the number of parts being $N$. The work done in dividing the water will be $4 \pi$ $r^{2} \mathrm{~N} \cdot 000825$. For the volume of all the parts we have $\frac{4}{3} \pi$ $r^{3} \mathrm{~N}$. This volume is, in accordance with the requirements of the kinetic theory of gases, about $\frac{1}{3000}$ of the total volume of the steam. The volume of the steam is 1752 times the original unit volume of water. Hence-

$$
\begin{aligned}
\frac{4}{3} \pi r^{3} \mathrm{~N} 3000 & =1752 \\
4 \pi r^{2} \mathrm{~N} \cdot 000825 & =636 \cdot 7423
\end{aligned}
$$

One unit of heat equals 423 units of work.

Solving these equations for $r$ and $\mathrm{N}$, we get $r=\cdot 000000005$ centimetre, a quantity closely corresponding with the previous results of Sir William Thomson, Maxwell, and others ; and $\mathrm{N}$

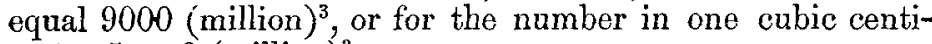
metre 5 to 6 (million) $)^{3}$.

Around every body there is an atmosphere of more or less condensed gases. On the surface of platinum these must be nearly in the liquid condition, as shown by the power of platinum to bring the atoms of oxygen and bydrogen so near together that they combine. These vapours on the surface have a tendency at ordinary temperatures to expand; and part of them can do so, if the surface of the body is reduced. There is in these condensed atmospheres an explanation of all the phenomena of superficial tension. The energy in the unit of area ought to be equal to the work done in compressing a

* Communicated by the Author. 
quantity of the vapour from the gaseous to the liquid state sufficient to cover the surface a few molecules deep. The molecular attraction seems to be very slight in gases, where the molecules are ten or fifteen molecular diameters apart. To get some idea of the amount of work done in compressing one gramme of oxygen to the liquid state, we may consider that in the union of one gramme of hydrogen with eight grammes of oxygen 34,462 units of heat are produced. It matters not that the condensation is brought about by the energy of chemical separation rather than by the work done in pressing them together in a cylinder.

The superficial energy of platinum is $169 \cdot 4$ metre-grammes per square metre, or -01694 per square centimetre, equal to -00004 of a unit of heat. The proportion

$$
9: 34,462=x: \cdot 00004
$$

gives the weight of water condensed on one square centimetre of surface, or the volume in cubic centimetres as 00000001 , which is the thickness of the layer, or diameter possibly, of the molecules.

Physical Laboratory, Harvard College, May 14, 1879.

IX. On a new Form of Spectrometer, and on the Distribution of the Intensity of Light in the Spectrum. By JOHN WILIIAM Draper, M.D., President of the Faculty of Science in the University of New York*.

T HAVE invented a spectrometer which, I think, opens a 1 new and interesting field to those who are engaged in spectrum-analysis.

The ordinary spectroscope is occupied with the frequency of xther-vibrations or wave-lengths. That which $\mathrm{I}$ am about to describe has a different function. It deals with the intensity or brilliancy of light. It depends on the well-known optical principle that a light becomes invisible when it is in presence of another light about sixty-four times more brilliant.

In some researches published by me in 1847 , on the production of light by heat, or the incandescence of bodies, I used this method as a photometer, and became sensible of its value. The memoir in which those experiments are related may be found in my recently published 'Scientific Memoirs,' page 23.

Having also published in 1872 a memoir on the distribution of heat in the prismatic spectrum, and shown that the course

* Communicated by the Author. 